\title{
La distribución territorial de competencias en la Federación venezolana
}

\author{
Allan R. Brewer-Carías \\ Catedrático de Derecho Público \\ Universidad Central de Venezuela
}

\begin{abstract}
SUMARIO: I. INTRODUCCIÓN. II. LAS MATERIAS DE COMPETENCIA EXCLUSIVA. III. LAS COMPETENCIAS CONCURRENTES ENTRE LOS NIVELES TERRITORIALES DEL PODER PÚBLICO. IV. LAS COMPETENCIAS RESIDUALES. V. EL PRINCIPIO DESCENTRALIZADOR EN LAS COMPETENCIAS DEL PODER PÚBLICO.
\end{abstract}

\section{INTRODUCCIÓN}

Si alguien se ocupó con maestría del tema de la descentralización política en el mundo hispano contemporáneo ese fue nuestro querido amigo Sebastián Martín-Retortillo Baquer. Todos los que nos dedicamos al Derecho administrativo recordamos, así, la aparición en 1973 de la magistral obra colectiva que dirigió sobre Descentralización administrativa y Organización Política en la cual, para el momento, se plantearon temas que eran absolutamente novedosos; y todos apreciamos, en su momento, la fundamental labor de chano como ministro del gobierno español en la construcción del esquema del Estado de las Autonomías. Por ello, precisamente, para este número homenaje a su memoria hemos querido dedicar este estudio al tema de la descentralización política, pero en una Federación como la venezolana, la cual, a pesar de ello, en muchos aspectos es menos descentralizada políticamente que el Estado de Autonomías español.

En efecto, siguiendo la tradición constitucional que se remonta a $1811^{1}$, la Constitución venezolana de $1999^{2}$ conservó la organización del Estado con forma federal, estableciendo una distribución del Poder Público en tres niveles: Nacional, Estadal y Municipal; atribuyendo su ejercicio a diversos órganos, y asignando competencias exclusivas en los tres niveles, además de las competencias concurrentes entre ellos, y algunas competencias residuales e implícitas.

\footnotetext{
${ }^{1}$ Véase sobre la evolución del Estado en Venezuela Allan R. BREWER-CARÍAs, Evolución histórica del Estado, Tomo I, Instituciones Políticas y Constitucionales, Caracas, 1996.

${ }^{2}$ Véase el texto comentado de la Constitución de 1999 (G.O. N. 36.860 de 30-12-1999) en Allan R. BREwER-CARÍAs, La Constitución de 1999, Caracas, 2000.
} 
En el artículo 136 de la Constitución se dispone entonces que «El Poder Público se distribuye entre el Poder Municipal, el de los Estados y el Nacional...», lo que implica el reconocimiento de autonomías territoriales en el nivel intermedio, es decir, de los Estados federados, los que antes de 1864 se denominaban. Provincias. En esa fecha, el triunfo de la Revolución Federal precisamente condujo a la adopción definitiva de la forma federal del Estado, que sustituyó a la fórmula mixta de 1830, que a la vez había sustituido a la «Confederación» de 1811; adoptándose la denominación de la República como «Estados Unidos de Venezuela», la que se conservó hasta 1953. Pero la Federación venezolana a partir de 1901 cuando se produjo el colapso del sistema de Estado Federal liberal que se había instaurado en 1864, progresivamente comenzó a ser una «Federación centralizada» por la concentración en el nivel nacional de casi todos los poderes; situación que ha continuado hasta la actualidad a pesar del cambio político democrático de 1946 y luego, del desarrollado a partir de 1958.

La gran transformación política que debió haber ocurrido en el proceso constituyente de 1999, debió consistir en la sustitución efectiva de la Federación Centralizada por una Federación Descentralizada. Grandes esfuerzos se hicieron en la materia; pero la profundización de la descentralización política como forma de perfeccionar la democracia que debió ser el tema central del debate constituyente ${ }^{3}$, no pasó del nominalismo expresado tanto en el Preámbulo como en el artículo 4 que precisa que «La República Bolivariana de Venezuela es un Estado federal descentralizado en los términos consagrados por esta Constitución»; fórmula más o menos similar a la del artículo 2 de la Constitución de 1961 que decía que «La República de Venezuela es un Estado federal, en los términos consagrados por esta Constitución».

En uno u otro caso, «los términos consagrados por la Constitución» son la clave para determinar efectivamente el grado de descentralización del Estado y, por tanto, de la Federación; y la comparación entre unos y otros «términos» revela muy poca diferencia. Puede decirse que en la Constitución de 1999, salvo en el nominalismo, no se avanzó mayormente en rela-

\footnotetext{
${ }^{3}$ Véanse nuestros planteamientos durante las sesiones de la Asamblea Nacional Constituyente de 1999 en Allan R. BREWER-CARÍAS, «Propuesta sobre la forma federal del Estado en la nueva Constitución: Nuevo Federalismo y Nuevo Municipalismo» en Debate Constituyente (Aportes a la Asamblea Nacional Constituyente), Tomo I, (8 agosto-8 septiembre), Caracas 1999, pp. 155 a 170). Véase también, Allan R. BREWER-CARÍAS «El reforzamiento de la forma federal del Estado Venezolano en la Nueva Constitución: Nuevo Federalismo y Nuevo Municipalismo», Ponencia presentada en The International Conference on Fereralism in an Era of globalization, Québec, Canadá octubre 1999 (mimeo), 13 pp.
} 
ción con lo que existía en el texto de $1961^{4}$. En realidad, sólo se constitucionalizaron aspectos ya establecidos en la Ley Orgánica de Descentralización, Delimitación y Transferencia de Competencias del Poder Público de $1989^{5}$, que ya tenía rango de ley constitucional en lo que se refería a la transferencia a los Estados de competencias del Poder Nacional. Pero no hubo los avances y transformaciones que eran necesarias para hacer realidad la descentralización política de la Federación; y más bien se retrocedió institucionalmente al eliminarse el Senado y establecerse una Asamblea Nacional Unicameral (art. 186), y al permitirse la limitación por Ley nacional de la autonomía de los Estados (art. 162) y de los Municipios (art. 168) lo que implica negar, de entrada, la idea misma de descentralización política que tiene que estar basada en el concepto de autonomía territorial.

En consecuencia, la denominación de «Federación Descentralizada» para identificar la forma del Estado que trae la Constitución es, sin duda, un avance nominal, que en «los términos establecidos» en la misma no significa realmente avance alguno, sino consolidación y mantenimiento parcial de reformas que se habían venían realizando desde 1989 hasta 1994, con algunos retrocesos.

Ahora bien, como toda Federación, así sea centralizada, la venezolana está montada sobre el principio de la distribución territorial del Poder Público entre tres niveles de gobierno: Municipal, Estadal y Nacional»; distribución que debe regirse, conforme lo indica el artículo 4 de la Constitución, «por los principios de integridad territorial, cooperación, solidaridad, concurrencia y corresponsabilidad».

Es decir, la distribución territorial del Poder Público no puede en forma ni caso alguno atentar contra la integridad territorial de la República, cuyo territorio no puede ser afectado por el principio descentralizador, lo que impide cualquier intento separatista de parte de las entidades políticas que componen el Estado.

Por otra parte, la distribución del Poder Público entre la República, los Estados y los Municipios, exige la cooperación entre los diversos niveles territoriales para alcanzar en conjunto, los fines del Estado (art. 136); por ello, los principios de la concurrencia y corresponsabilidad de todos los

\footnotetext{
${ }^{4}$ Véase lo que hemos expuesto en Allan R. Brewer-Carías, Federalismo y Municipalismo en la Constitución de 1999 (Alcance de una reforma insuficiente y regresiva), Caracas, 2001.

${ }^{5}$ Véase Allan R. BREWER-CARÍAS et al., Leyes y reglamentos para la descentralización política de la Federación, Caracas, 1994.
} 
entes públicos hacia los mismos fines superiores del Estado. Además, está el principio de la solidaridad entre las entidades políticas, de manera que los deberes de algunas de ellas que no puedan ser cumplidos, no excluye la asunción de los mismos por las otras entidades políticas.

Además de los anteriores principios, el artículo 165 de la Constitución, que se refiere a las materias de competencia concurrente entre los tres niveles territoriales del Poder Público (República, Estados y Municipios), exige que las mismas sean desarrolladas mediante leyes de bases dictadas por la Asamblea Nacional y leyes de desarrollo aprobadas por los Estados, legislación que debe estar orientada por los principios de interdependencia, coordinación, cooperación, corresponsabilidad y subsidiariedad.

En cuanto al principio de interdependencia, éste implica que los niveles territoriales, en el ejercicio de las competencias concurrentes, deben tener relaciones de dependencia, unos respecto de otros, en forma recíproca y mutua, para lo cual la coordinación de esfuerzos es fundamental. Esta coordinación debe realizarse, fundamentalmente, por un órgano intergubernamental que se creó en la Constitución de 1999, como es el Consejo Federal de Gobierno (art. 185).

Por último, se destaca el principio de la subsidiariedad en la distribución de competencias. Si «el Poder Público se distribuye entre el Poder Municipal, el Poder Estadal y el Poder Nacional», «colocados en este orden según su cercanía con el ciudadano, sujeto protagónico de este modelo de democracia participativa» según lo expresa la Exposición de Motivos de la Constitución; el principio general para la asignación de competencias debería estar en el nivel municipal, debiendo ser asumidas las mismas en niveles superiores sólo en forma subsidiaria, cuando no puedan efectivamente desarrollarse a nivel local.

Ahora bien, la distribución vertical del Poder Público entre el Poder Municipal, el Poder Estadal y el Poder Nacional en los términos definidos en el artículo 136 de la Constitución, conduce a una distribución de competencias entre los distintos órganos que ejercen el Poder Público: el Poder Público Nacional, el Poder Público Estatal y el Poder Público Municipal. Esta distribución de competencias permite distinguir entre las atribuciones asignadas a los órganos de los tres niveles territoriales; y las materias sobre las cuales se ejercen las atribuciones en los tres niveles territoriales (arts. 156, 164, 178 y 179).

En efecto, cuando el artículo 156 de la Constitución dispone que «Es de la competencia del Poder Público Nacional...», en el texto enumera un 
conjunto de materias que corresponden a los órganos del Poder Nacional pero sin precisar si son competencias exclusivas o no. En esa enumeración, en realidad, hay materias que son tanto de la competencia exclusiva del Poder Nacional como de competencia concurrente con otros niveles territoriales. En este artículo 156 de la Constitución, por supuesto, no se regulan las atribuciones que corresponden a cada uno de los órganos del Poder Público Nacional las cuales se asignan en forma aparte en forma de exclusiva: a la Asamblea Nacional, por ejemplo, la atribución de «legislar en las materias de la competencia nacional» (art. 178,1); al Presidente de la República, por ejemplo, administrar la Hacienda Pública Nacional (art. 236,11); y al Tribunal Supremo de Justicia, por ejemplo, ejercer el control de la constitucionalidad de las leyes (art. 336,1).

En cuanto a los Municipios, la distinción normativa entre atribuciones y materias sobre las cuales se ejercen las atribuciones también está establecida en la Constitución: en el artículo 178 se regula «la competencia del Municipio» traducida en un conjunto de materias que no son de ejercicio exclusivo; y en los artículos 174 y siguientes se precisan las atribuciones de los órganos del Poder Público Municipal, las cuales, por supuesto, son de carácter exclusivo: al Consejo Municipal se asigna la competencia para ejercer la «función legislativa del Municipio» (art. 175) y al Alcalde, la competencia para ejercer «el gobierno y la administración del Municipio» (art. 174).

En relación con los Estados, la distinción de regulación normativa antes indicada que existe en relación al Poder Nacional y al Poder Municipal no es tan precisa. El artículo 164 de la Constitución, cuando enumera la «competencia exclusiva de los Estados», mezcla un conjunto de atribuciones con materias sobre las cuales se ejercen dichas atribuciones. Por ejemplo, al indicar que «es de la competencia exclusiva de los Estados»: «dictar su propia Constitución» (ord. 1), «la organización de sus Municipios» (ord. 2) y «administrar sus bienes» (ord. 3), está precisando, en realidad, atribuciones de los órganos que ejercen el Poder Público en cada Estado; pero cuando enumera dentro de las mismas «competencias exclusivas» «la ejecución, conservación, administración y aprovechamiento de las vías terrestres estadales» (ord. 9), está indicando una «materia» de la competencia estadal, de carácter exclusivo, que deben ejercer los órganos de cada Estado conforme a sus respectivas atribuciones.

Para ello, la Constitución en otras normas precisa el detalle de esas atribuciones: al Consejo Legislativo le asigna la atribución de «legislar sobre las materias de la competencia estadal» (art. 162,1) y al Gobernador del Estado la de ejercer «el gobierno y administración de cada Estado» (art. 160). 
De lo anterior resulta que si bien las atribuciones de los diversos órganos del Poder Público, tanto Nacional como Estadal y Municipal son siempre «competencias» de carácter exclusivo (dentro de las limitaciones constitucionales); en cambio, no todas las competencias en el sentido de materias sobre las cuales se ejercen las atribuciones, son atribuidas en forma exclusiva a los órganos del Poder Público. En algunos casos, sí son materias de la competencia exclusiva de los distintos niveles territoriales; en otros casos, son materias de competencias concurrentes; en otros, se trata de materias de competencia residual ${ }^{6}$.

Analizaremos, separadamente, las competencias de los niveles territoriales del Poder Público (Poder Nacional, Poder Estadal, Poder Municipal), en el sentido de las materias sobre las cuales sus órganos ejercen sus atribuciones, distinguiendo las materias de competencia exclusiva, concurrente y residual.

\section{LAS MATERIAS DE COMPETENCIA EXCLUSIVA}

Las materias de la competencia exclusiva, como su nombre lo indica, son las atribuidas a cada uno de los niveles territoriales del poder público para ser ejercidas por sus órganos constitucionales en forma exclusiva y excluyente respecto de otros órganos del poder público.

\section{Las materias de la competencia exclusiva de los órganos del Poder Público Nacional}

En la misma tradición del artículo 136 de la Constitución de 1961, el artículo 156 de la Constitución de 1999 enumera un conjunto de materias de la competencia del Poder Nacional. En algunos casos, la enunciación de la «materia» de la competencia exclusiva, se hace con carácter global, abarcando toda la materia; en otros casos, la indicación de la materia se hace atribuyendo al Poder Nacional sólo un aspecto de la misma.

A. Las materias relativas al régimen político y a la organización del Estado nacional

\section{a. Las relaciones internacionales}

\footnotetext{
${ }^{6}$ Para esta sistematización seguimos lo que hemos expuesto en el libro Allan R. BREWER-CARÍAS, Federalismo y Municipalismo, cit., pp. 46 y ss.
} 
Corresponde al Poder Nacional, conforme al artículo 156,1 de la Constitución, «La política y la actuación internacional de la República» (art. 152 y sigts.).

Adicionalmente se debe agregar la competencia para la aprobación y ratificación de los tratados internacionales (art. 154).

b. Las cuestiones de seguridad y defensa

El mismo artículo 156,2 atribuye al Poder Nacional

2. La defensa y suprema vigilancia de los intereses generales de la República, la conservación de la paz pública y la recta aplicación de la ley en todo el Territorio Nacional.

7. La seguridad, la defensa y el desarrollo nacional (arts. 326 y sigts.).

8. La organización y régimen de la Fuerza Armada Nacional (arts. 328 y sigts.).

30. El manejo de la política de fronteras con una visión integral del país, que permita la presencia de la venezolanidad y el mantenimiento territorial y la soberanía en esos espacios (arts. 15 y 327).

\section{c. El régimen de los símbolos patrios}

El artículo 156,3 atribuye al Poder Nacional competencia en materia de «La bandera, escudo de armas, himno, fiestas, condecoraciones y honores de carácter nacional» (art. 8).

\section{d. El estatuto de las personas}

El artículo 156 atribuye al Poder Nacional competencia en materia de:

4. La naturalización, la admisión, la extradición y expulsión de extranjeros o extranjeras (art. 38).

5. Los servicios de identificación

\section{e. El régimen de la división territorial}

El artículo 156,10 atribuye al Poder Nacional competencia para la organización y régimen del Distrito Capital y de las dependencias federales (arts. 17 y 18).

Adicionalmente, conforme al artículo 16, también corresponde al Poder Nacional la división político-territorial de la República, la creación y régimen de los Territorios Federales y el régimen municipal (art. 169). 


\section{f. $\quad$ El régimen de los Poderes Públicos Nacionales}

El mismo artículo 156,31 atribuye al Poder Nacional competencia para «La organización y administración nacional de la justicia, el Ministerio Público y el Defensor del Pueblo».

Además, corresponde al Poder Nacional la legislación sobre la organización y funcionamiento de todos los órganos del Poder Público Nacional y de los demás órganos e instituciones nacionales del Estado (ord. 32).

\section{B. Las materias relativas a la policía nacional y seguridad ciudadana}

\section{a. La policía nacional}

El ordinal $6 .^{\circ}$ del artículo 156 atribuye competencia exclusiva al Poder Nacional en materia de «policía nacional», lo que implica que no toda la materia relativa a la policía que regula la Constitución (art. 332) corresponde al Poder Nacional. Se trata de una materia distribuida entre los diversos niveles territoriales. Sin embargo, lo que es materia de competencia exclusiva del Poder Nacional es la policía nacional.

b. El régimen de la administración de riesgos y emergencias

El ordinal 9 del artículo 156 de la Constitución atribuye al Poder Nacional competencia en materia de «El régimen de la administración de riesgos y emergencias», como parte de la función de seguridad ciudadana que regula la Constitución (arts. 52 y 332).

Lo que se atribuye al Poder Nacional como competencia exclusiva en esta materia es el «régimen» y la creación de «un cuerpo de bomberos y administración de emergencias de carácter civil» y «una organización de protección civil y administración de desastres» (art. 332); existiendo otros aspectos que son de la competencia concurrente con los Estados y Municipios.

\section{Las materias relativas al régimen económico}

\section{a. El régimen general de la economía}

De acuerdo con el artículo 156, se atribuye al Poder nacional competencia en las siguientes materias que corresponden al régimen económico general:

11. La regulación de la banca central, del sistema monetario, de la moneda extranjera, del sistema financiero y del mercado de capitales; la emisión y acuñación de moneda. 
15. El régimen del comercio exterior y la organización y régimen de las aduanas.

17. El régimen de metrología legal y control de calidad

18. Los censos y estadísticas nacionales.

21. Las políticas macroeconómicas, financieras y fiscales de la República.

Además, corresponde al Poder Nacional la legislación antimonopolio (art. 113) y la que regule los ilícitos económicos (art. 114).

b. El régimen del correo y las telecomunicaciones

El mismo artículo 156 le atribuye al Poder Nacional competencia en materia de:

28. El régimen de servicio de correo y de las telecomunicaciones, así como el régimen y la administración del espectro electromagnético

\section{c. Régimen y administración de las minas}

El artículo 156, ord. 16, de la Constitución atribuye al Poder Nacional competencia en materia de «El régimen y administración de las minas e hidrocarburos».

La materia minera, sin embargo, también está atribuida a los Estados, en relación con el «régimen y administración de minerales no metálicos...; las salinas... de conformidad con la ley» (art. 164,5).

\section{d. El régimen de las tierras baldías}

El Poder Nacional tiene competencia en materia de «régimen de las tierras baldías» (art. 156,16).

La Constitución, por otra parte, atribuye a los Estados «la administración de las tierras baldías en su jurisdicción, de conformidad con la ley» (art. 164,5).

\section{e. Los recursos naturales renovables}

El artículo 156,16 asigna al Poder Nacional competencia en materia de «la conservación, fomento y aprovechamiento de los bosques, suelos, aguas y otras riquezas naturales del país».

Por su parte, el artículo 164,5 atribuye a los Estados competencias sobre «los ostrales... de conformidad con la ley». 


\section{f. La ordenación nacional del ambiente y de la ocupación del territorio}

El artículo 156 de la Constitución atribuye como competencia exclusiva del Poder Nacional «las políticas nacionales y la legislación en materia ... (de) ambiente, aguas... y ordenación del territorio» (ord. 23); y «la legislación sobre ordenación urbanística» (ord. 19).

Las políticas estadales y municipales en esas materias, por tanto, corresponden a los Estados y Municipios.

\section{g. Las obras de infraestructura}

\section{a'. La ordenación normativa de las obras de infraestructura}

Corresponde en forma exclusiva al Poder Nacional regular el sistema normativo de las obras de infraestructura, para lo cual el artículo 156 le asigna competencia para:

«19. El establecimiento, coordinación y unificación de normas y procedimientos técnicos para obras de ingeniería, de arquitectura y de urbanismo...»

Además, corresponde al Poder Nacional la competencia para establecer «el régimen ... de los puertos, aeropuertos y su infraestructura» (art. $156,26)$.

\section{b'. Las obras públicas nacionales}

En materia de obras públicas, la Constitución asigna competencia exclusiva al Poder Nacional, en materia de «obras públicas de interés nacional» (art. 156,20), por lo que la competencia en materia de obras públicas estadales y municipales corresponde, respectivamente, a los Estados y Municipios.

\section{c'. La vialidad nacional}

Conforme al artículo 156, ord. 27, corresponde en forma exclusiva al Poder Nacional:

27. El sistema de vialidad y de ferrocarriles nacionales.

Lo que se reserva al Poder Nacional no es la vialidad, sino el sistema (se entiende, nacional) de vialidad nacional. Por ello los Estados y Municipios tienen competencia en materia de vialidad estadal y municipal. 


\section{h. El transporte nacional}

El artículo 156,26 de la Constitución atribuye competencia exclusiva al Poder Nacional, en materia de:

26. El régimen de la navegación y del transporte aéreo, terrestre, marítimo fluvial y lacustre, de carácter nacional...

El ordinal 27, además, atribuye al Poder Nacional competencia en materia de «ferrocarriles nacionales».

En consecuencia, también puede haber transporte estadal y municipal, cuyo régimen compete a Estados y Municipios. Sin embargo, sólo compete al Poder Nacional «las políticas nacionales y la legislación en materia naviera» (art. 156,23), lo que no excluye que pueda haber políticas estadales y municipales en esa materia.

\section{i. La política nacional y la ordenación normativa del turismo}

El ordinal 23 del mismo artículo 156 atribuye al Poder Nacional competencia en materia de «las políticas nacionales y la legislación en materia de ... turismo»; lo que no excluye las competencias de los Estados y Municipios en las políticas estadales y municipales de turismo.

\section{j. Las políticas nacionales para la producción agropecuaria}

Corresponde a la competencia del Poder Nacional, conforme al artículo 156 , ord. 25 de la Constitución,

25. Las políticas nacionales para la producción agrícola, ganadera, pesquera y forestal.

El ordinal 23 del mismo artículo, además, atribuye al Poder Nacional «las políticas nacionales y la legislación en materia de ... seguridad alimentaria».

En consecuencia, sólo se reserva al Poder Nacional las políticas nacionales en esta materia, lo que permite el desarrollo por los Estados y Municipios, de políticas estadales y municipales en la misma materia.

\section{k. El régimen general de los servicios públicos domiciliarios}

El ordinal 29 del artículo 156 de la Constitución atribuye al Poder Nacional competencia en materia de:

29. El régimen general de los servicios públicos domiciliarios y en especial, electricidad, agua potable y gas.

La exclusividad de la competencia nacional en esta materia sólo se refiere al «régimen general» de los servicios, pero no al régimen particu- 
lar y la prestación que puede corresponder a los Estados (art. 164,8) y Municipios $(178,6)$.

D. Las materias relativas al régimen del desarrollo social

a. El régimen de la seguridad social

El artículo 156, 22 establece en general que corresponde al Poder Nacional:

22. El régimen y organización del sistema de seguridad social.

b. Régimen nacional de la vivienda

Corresponde al Poder Público Nacional competencia en materia de «las políticas nacionales y la legislación en materia de vivienda» (art. 156,23), lo que no excluye las competencias estadales y municipales en materia de política de vivienda.

c. La política relativa a los servicios públicos nacionales de educación y salud

El ordinal 23 del artículo 156 de la Constitución atribuye al Poder Nacional competencia en materia de «las políticas nacionales y la legislación en materia... de sanidad»; y el ordinal 24, competencia en cuanto a:

24. Las políticas y los servicios nacionales de educación y salud.

E. Las competencias tributarias nacionales y la regulación del régimen tributario estadal y municipal

La Constitución de 1999 siguió la tendencia constitucional anterior de vaciar a los Estados de competencias tributarias, y centralizó aún más el Estado al atribuir al Poder Nacional potestad para regular y limitar el ejercicio de sus competencias, por los Estados y Municipios, lo que constituye una contradicción con la declaración de los Estados y Municipios como entidades autónomas (art. 159, 168).

El artículo 156, ordinal 12, de la Constitución define el ámbito de la competencia exclusiva del Poder Nacional en relación con la potestad tributaria, y establece cuáles son los tributos nacionales:

12. La creación, organización, recaudación, administración y control de los impuestos sobre la renta, sobre sucesiones, donaciones y demás ramos conexos, el capital, la producción, el valor agregado, los hidrocarburos y minas, de los gravámenes a la importación y exportación de bienes y servicios, los impuestos que recaigan sobre el 
consumo de licores, alcoholes y demás especies alcohólicas, cigarrillos y demás manufacturas del tabaco, y los demás impuestos, tasas y rentas no atribuidas a los Estados y Municipios por esta Constitución y la ley.

Se destaca, de esta norma, la asignación de competencia residual a favor del Poder Nacional, en toda materia tributaria no atribuida por la Constitución y la ley a los Estados y Municipios, con lo cual se restringió aún más en esta materia, la competencia tributaria estadal.

Además, corresponde al Poder Nacional, conforme al mismo artículo 156, lo siguiente:

14. La creación y organización de impuestos territoriales o sobre predios rurales y sobre transacciones inmobiliarias, cuya recaudación y control corresponda a los Municipios, de conformidad con esta Constitución.

Los Municipios, en efecto, conforme al artículo 179,3 tienen entre sus ingresos «El impuesto territorial rural o sobre predios rurales, la participación en la contribución de mejoras y otros ramos tributarios nacionales o estadales, conforme a las leyes de creación de dichos tributos».

Pero además de estas competencias tributarias propias, como se ha señalado, la Constitución asigna al Poder Nacional competencia expresa para intervenir en el ejercicio de las competencias tributarias de Estados y Municipios, al disponer, el artículo 156, la competencia del Poder Nacional para dictar:

13. La legislación para garantizar la coordinación y armonización de las distintas potestades tributarias, definir principios, parámetros y limitaciones, especialmente para la determinación de los tipos impositivos o alícuotas de los tributos estadales y municipales, así como para crear fondos específicos que aseguren la solidaridad interterritorial.

Además, corresponde al Poder Nacional, mediante Ley, regular la participación de los Estados en los tributos nacionales (arts. 164,3 y 167,6) y asignar a los Estados impuestos, tasas y contribuciones especiales con el fin de promover el desarrollo de las haciendas públicas estadales (art. 167,5). En este último caso, de leyes que creen o transfieran ramos tributarios a favor de los Estados, las mismas podrán compensar dichas asignaciones con modificaciones de los ramos de ingresos de los Estados, a fin de preservar la equidad interterritorial (art. 167,5).

En todos estos casos de leyes nacionales que se refieren a los Estados, la Asamblea Nacional está obligada a consultarlos a través de los Consejos Legislativos Estadales, antes de la sanción de las mismas (art. 206). Ello implica que también los Estados y Municipios tienen competencia en 
materia de políticas y servicios estadales y municipales de educación y salud.

\section{F. La competencia en materia de legislación general}

De acuerdo con el artículo 156,32, el Poder Nacional, además de las competencias legislativas que tiene respecto de las materias que se le atribuyen, tiene las siguientes competencias generales de legislación:

32. La legislación en materia de derechos, deberes y garantías constitucionales; la civil, mercantil, penal, penitenciaria, de procedimientos y de derecho internacional privado; la de elecciones; la de expropiación por causa de utilidad pública o social; la de crédito público; la de propiedad intelectual, artística e industrial; la del patrimonio cultural y arqueológico; la agraria; la de inmigración y poblamiento; la de pueblos indígenas y territorios ocupados por ellos; la del trabajo, previsión y seguridad sociales; la de sanidad animal y vegetal; la de notarías y registro público; la de bancos y la de seguros; la de loterías, hipódromos y apuestas en general; la de organización y funcionamiento de los órganos del Poder Público Nacional y demás órganos e instituciones nacionales del Estado; y la relativa a todas las materias de la competencia nacional.

Al tratarse de legislación que se refiere al régimen civil de propiedad sobre bienes, también compete al Poder Nacional la legislación sobre el dominio público de las costas (art. 12), las aguas (art. 304) y las riquezas del subsuelo (art. 12).

\section{Las materias de la competencia exclusiva del poder público estadal}

Al contrario de lo que sucede con el artículo 156 de la Constitución relativo a las materias de la competencia del Poder Nacional, antes analizado, el artículo 164 del mismo texto cuando enumera la competencia exclusiva de los Estados, mezcla atribuciones con materias sobre las cuales se ejercen las mismas.

En efecto, los ordinales 1, 2 y 3 del artículo 164 en realidad lo que definen son atribuciones generales exclusivas de los órganos de los Poderes Públicos Estadales, que en particular corresponden a los Consejos Legislativos y al Gobernador de cada Estado, así:

1. Dictar su Constitución para organizar los poderes públicos.

2. La organización de sus Municipios y demás entidades locales y su división política territorial, conforme a esta Constitución y a la ley.

3. La administración de sus bienes y la inversión y administración de sus recursos, incluso de los provenientes de transferencias, subvenciones o asignaciones especiales del Poder 
Nacional, así como de aquellos que se les asignan como participación en los tributos nacionales

Sin embargo, a pesar de que éstas se califican como atribuciones exclusivas, la propia Constitución las limita, al atribuir al Poder Nacional, por ejemplo, competencia para que la Asamblea Nacional pueda regular por ley, la organización y funcionamiento de los Consejos Legislativos Nacional o el nombramiento de los Contralores estadales, que integran los poderes públicos de los Estados los cuales sólo deberían estar regulados en las Constituciones de los Estados (art. 164, 1).

Ahora bien, en relación con las materias de la competencia exclusiva de los Estados enumeradas en el artículo 164 de la Constitución las mismas, en general, pueden considerarse como de competencia exclusiva parcial, pues otros aspectos de las mismas materias se asignan a otros órganos del Poder Público.

\section{A. La policía estadal y el ámbito de la policía municipal}

Conforme a dicho artículo 164, los Estados tienen como materia de la competencia exclusiva:

6. La organización de la policía y la determinación de las ramas de este servicio atribuidas a la competencia municipal, conforme a la legislación nacional aplicable.

Esta competencia exclusiva, sin embargo, como lo dispone la norma, debe ejercerse por los Estados «conforme a la legislación nacional aplicable», lo que implica una sujeción al régimen general de la policía que establezca el Poder Nacional.

\section{B. Competencias en materia económica}

\section{a. El régimen de los minerales no metálicos y las salinas}

El artículo 164,5 de la Constitución asigna competencia a los Estados en cuanto al

régimen y aprovechamiento de minerales no metálicos, no reservados al Poder Nacional, las salinas ..., de conformidad con la ley.

Esta materia de la competencia exclusiva se había transferido a los Estados por el artículo 11,2 de la Ley Orgánica de Descentralización, Delimitación y Transferencia de Competencias del Poder Público de $1989^{7}$.

\footnotetext{
${ }^{7}$ Véase en G. $O$. N N. $^{\circ} 4.153$ Extraordinaria de 28-12-98.
} 
Ahora bien, en cuanto a su ejercicio, en todo caso, queda sujeta al régimen general que el Poder Nacional puede establecer sobre «las minas e hidrocarburos... y otras riquezas naturales del país» (art. 156,16).

\section{b. La administración de las tierras baldías}

El artículo 164,5 de la Constitución asigna a los Estados competencia para «la administración de las tierras baldías en su jurisdicción».

Esta competencia, sin embargo, debe ejercerse conforme al régimen de las tierras baldías que establezca el Poder Nacional (art. 156,16). En todo caso, conforme a la Disposición Transitoria Décimo Primera de la Constitución, «hasta tanto se dicte la legislación nacional relativa al régimen de las tierras baldías, la administración de las mismas continuará siendo ejercida por el Poder Nacional, conforme a la legislación vigente».

\section{c. Los ostrales}

Los Estados tienen competencia en relación con «los ostrales... de conformidad con la ley» (art. 164,5).

Por supuesto, correspondiendo al Poder Nacional la competencia general respecto de «la conservación, fomento y aprovechamiento de los bosques, suelos, aguas y otras riquezas naturales del país» (art. 156,16), los Estados están sujetos a esa regulación general al ejercer su competencia en relación con los ostrales.

\section{d. Las obras públicas estadales}

Al atribuirse al Poder Nacional competencia exclusiva en materia de obras públicas nacionales (art. 156,20), corresponde a los Estados la competencia exclusiva en materia de obras públicas estadales.

\section{e. Los servicios públicos estadales}

El artículo 164,8 de la Constitución atribuye a los Estados competencia exclusiva en materia de:

La creación, régimen y organización de los servicios públicos estadales.

En ninguna norma constitucional se atribuye a los Estados competencias en materia de servicios públicos específicos, por lo que esta materia, en realidad, se configura como una materia de la competencia concurrente con otros niveles del Poder Público, como las referidas a los servicios de salud, educativos o de deportes, por ejemplo. 
En todo caso, la competencia estadal en materia de servicios públicos se corrobora por lo dispuesto en el artículo 184 de la Constitución.

\section{f. La vialidad estadal}

La Constitución atribuye a los Estados competencia exclusiva en materia de:

La ejecución, conservación, administración y aprovechamiento de las vías terrestres estadales (art. 164,9).

Las vías terrestres estadales son «las que conforman la red vial dentro del territorio de cada Estado, con exclusión de las vías de comunicación nacionales que se encuentren en el mismo y de las vías urbanas municipales», tal como las define el artículo 6 del Reglamento Parcial N. 7 de la Ley Orgánica de Descentralización, Delimitación y Transferencia de Competencias del Poder Público, en materia de vialidad terrestre ${ }^{8}$; siendo vías de comunicación nacionales «las carreteras que atraviesan un Estado y salgan de sus límites» (art. 4,1).

La precisión del ámbito de la materia objeto de esta competencia exclusiva es esencial, ya que el artículo 156 asigna al Poder Nacional competencia en cuanto al «Sistema de vialidad y de ferrocarriles nacionales» (ord. 27); y el artículo 178,2 atribuye a los Municipios competencia en materia de «vialidad urbana».

\section{g. La administración de la vialidad nacional}

Siguiendo la decisión adoptada por la Ley Orgánica de Descentralización, Delimitación y Transferencia de Competencias del Poder Público de 1989 (art. 11,3), el artículo 164,10 de la Constitución asigna competencia exclusiva a los Estados en materia de:

10. La conservación, administración y aprovechamiento de carreteras y autopistas nacionales... en coordinación con el Poder Nacional.

Esta competencia, por supuesto, no sólo está sujeta al ejercicio de la competencia nacional en materia de «sistema de vialidad y ferrocarriles nacionales» (art. 156,27) sino a «la coordinación con el Poder Nacional» que este debe regular.

\section{h. Administración de puertos y aeropuertos comerciales}

${ }^{8}$ Véase en G.O. N. ${ }^{\circ} 35.327$ de 28-10-93. 
La Constitución, siguiendo la descentralización de competencia efectuada a favor de los Estados por el artículo 11,5 de la Ley Orgánica de Descentralización, Delimitación y Transferencia de Competencias del Poder Público, también asigna competencia exclusiva a los Estados en materia de:

10. La conservación, administración y aprovechamiento de ... puertos y aeropuertos de uso comercial, en coordinación con el Poder Nacional».

En esta materia, sin embargo, la competencia estadal es de ejercicio parcial, pues el Poder Nacional tiene competencia en materia de «El régimen de... los puertos, aeropuertos y su infraestructura» (art. 156,26) y, en todo caso, la competencia estadal debe ejercerse «en coordinación con el Poder Nacional» conforme al régimen establecido en la legislación nacional.

\section{Los tributos estadales}

El artículo 164,4 asigna competencia exclusiva a los Estados en materia de:

La organización, recaudación, control y administración de los recursos tributarios propios, según las disposiciones de las leyes nacionales y estadales.

Esta competencia «exclusiva», sin embargo, conforme a la Constitución, es una competencia vacía de contenido ya que la propia Constitución no prevé «recursos tributarios propios» algunos de los Estados. Esos recursos dependen totalmente de la ley nacional que asigne a los Estados impuestos, tasas y contribuciones especiales «para promover el desarrollo de las haciendas públicas estadales» (art. 167,5). En consecuencia, no sólo la materia tributaria como competencia exclusiva es una competencia vacía en la Constitución, sino que su ejercicio depende íntegramente de la ley nacional.

En todo caso, la única competencia en relación con los tributos que se asigna directamente a los Estados, en forma exclusiva, es la creación, organización, recaudación, control y administración de los ramos de papel sellado, timbres y estampillas (art. 164,7). En tal sentido se declaran como ingresos estadales el producto de lo recaudado por venta de especies fiscales (art. 167,3). Sin embargo, debe destacarse que la Sala Constitucional del Tribunal Supremo de Justicia, en la sentencia del 13-12-00 dictada con motivo de la interpretación de la Ley Especial sobre el Distrito Metropolitano de Caracas, sobre este ramo fiscal ha señalado que la venta de especies fiscales es sólo «una forma de pago de los tributos» que puede ser 
explotado por cualquier ente público territorial para pechar los servicios que presta ${ }^{9}$.

De resto, los Estados no tienen otras competencias tributarias que las que le puedan serles asignadas expresamente por ley nacional. Así, el artículo 167,5 de la Constitución le atribuye a los Estados, como ingresos, los demás impuestos, tasas y contribuciones especiales que se le asignen por ley nacional, con el fin de promover el desarrollo de las haciendas públicas estadales; pudiendo la ley nacional, además asignar a los Estados participación en los tributos nacionales (arts. 164,3 y $167,6)$.

Los Estados, sin embargo, conforme al artículo 183 de la Constitución en ningún caso pueden:

1. Crear aduanas ni impuestos de importación, de exportación o de tránsito sobre bienes nacionales o extranjeros, o sobre las demás materias rentísticas de la competencia nacional.

2. Gravar bienes de consumo antes de que entren en circulación dentro de su territorio.

3. Prohibir el consumo de bienes producidos fuera de su territorio, ni gravarlos en forma diferente a los producidos en él.

Los Estados, además, sólo podrían gravar la agricultura, la cría, la pesca y la actividad forestal en la oportunidad, forma y medida que lo permita la ley nacional.

\section{Las materias de la competencia exclusiva del poder municipal}

\section{A. Las materias de la competencia exclusiva del Poder Municipal en cuanto concierne a la vida local}

El artículo 178 de la Constitución contiene una larga enumeración de materias que se atribuyen a los Municipios. Sin embargo, puede decirse que las mismas no son, en absoluto, materias de la competencia exclusiva de los mismos. Lo que es exclusivo de los Municipios son los aspectos de esas materias que «conciernen a la vida local», pero las materias, en sí mismas, abarcan competencias atribuidas al Poder Nacional y al Poder Estadal. Por ello, es la Ley Orgánica de Régimen Municipal la llamada a precisar los aspectos de las materias que con-

\footnotetext{
${ }^{9}$ Véase sentencia N. ${ }^{\circ} 1563$, de 13-12-00, pp, 55 de 61 y 56 de 61, en http:// www. tsj.gov.ve/ decisiones
} 
ciernen a la vida local y que serían de la competencia exclusiva de los Municipios.

En consecuencia, puede decirse que, conforme al artículo 178 de la Constitución, es competencia exclusiva de los Municipios «el gobierno y administración de sus intereses y la gestión de las materias que le asigne esta Constitución y las leyes nacionales, en cuanto concierne a la vida local», en particular, las siguientes:

1. La ordenación y promoción del desarrollo económico y social; la promoción de la participación y el mejoramiento, en general de las condiciones de vida de la comunidad (Encabezamiento);

2. La dotación y prestación de los servicios públicos domiciliarios; en particular, los servicios de agua potable, electricidad y gas doméstico, alcantarillado, canalización y disposición de aguas servidas; aseo urbano y domiciliario, comprendidos los servicios de limpieza, de recolección y tratamiento de residuos (Encabezamiento y ords. 4 y 6 );

3. Ordenación territorial y urbanística (ord. 1);

4. Patrimonio histórico (ord. 1);

5. Vivienda de interés social y aplicación de la política referente a la materia inquilinaria «con criterios de equidad, justicia y contenido de interés social de conformidad con la delegación prevista en la ley que rige la materia» (Encabezamiento y ord. 1);

6. Turismo local (ord. 1);

7. Parques y jardines, plazas, balnearios y otros sitios de recreación (ord. 1);

8. Arquitectura civil, nomenclatura y ornato público

9. Vialidad urbana (ord. 2);

10. Circulación y ordenación del tránsito de vehículos y personas por vías municipales (ord. 2);

11. Servicios de transporte público urbano de pasajeros (ord. 2);

12. Espectáculos públicos (ord. 3); 
13. Publicidad comercial, en cuanto concierne a los intereses y fines específicos municipales (ord. 3);

14. Protección del ambiente y cooperación con el saneamiento ambiental (ord. 4);

15. Protección civil; prevención y protección vecinal y servicios de policía municipal, conforme a la legislación nacional aplicable; y servicios de prevención y protección vigilancia y control de los bienes y las actividades relativas a las materias de la competencia municipal; (ords. 4, 5, y 6);

16. Salubridad y atención primaria a la salud (ord. 5);

17. Servicios de protección a la primera y segunda infancia, a la adolescencia y a la tercera edad (ord. 5);

18. Educación preescolar (ord. 5);

19. Servicios de integración familiar de la persona con discapacidad al desarrollo comunitario (ord. 5);

20. Actividades e instalaciones culturales (ord. 5);

21. Actividades deportivas (ord. 5);

22. Cementerios y servicios funerarios (ord. 6);

23. Justicia de paz (ord. 7).

A este listado debe agregarse la competencia municipal en materia de «obras públicas municipales» dado que el artículo 156,20 atribuye al Poder Nacional competencia exclusiva en materia de obras públicas nacionales.

Los Municipios, en consecuencia, tienen competencia exclusiva en relación a las anteriores materias, pero sólo en cuanto concierne a la vida local, ya que la gran mayoría de las mismas se configuran como materias de la competencia concurrente. En realidad sólo pueden identificarse como materias de la competencia exclusiva global del Poder Municipal, las siguientes:

— espectáculos públicos (ord. 3)

- cementerios y servicios funerarios (ord. 6) 
Sin embargo, a pesar de la exclusividad, la autonomía municipal en cuanto al ejercicio de las competencias municipales queda sujeta, en general, a las limitaciones que establezca la ley nacional (art. 168), lo que es una negación de la propia autonomía.

\section{B. Las competencias tributarias municipales}

De acuerdo con el artículo 171 de la Constitución, los Municipios tienen los siguientes ingresos tributarios:

1. Los impuestos sobre actividades económicas de industria, comercio, servicios, o de índole similar, con las limitaciones establecidas en esta Constitución (art. 179,2);

2. Los impuestos sobre inmuebles urbanos;

3. Los impuestos sobre vehículos,

4. Los impuestos sobre espectáculos públicos,

5. Los impuestos sobre juegos y apuestas lícitas;

6. Los impuestos sobre propaganda y publicidad comercial (art. 179,2);

7. El impuesto territorial rural o sobre predios rurales (art. 179,2) el cual debe ser creado y organizado por el Poder Nacional, correspondiendo la recaudación y control a los Municipios (art. 156,14);

8. El impuesto sobre transacciones inmobiliarias, el cual también debe ser creado y organizado por el Poder Nacional, correspondiendo la recaudación y control a los Municipios (art. 156,14);

9. La contribución especial sobre plusvalías de las propiedades generadas por cambios de uso o de intensidad de aprovechamiento con que se vean favorecidas por los planes de ordenación urbanística (art. 179,2);

10. La participación en la contribución por mejoras y otros ramos tributarios nacionales o estadales, conforme a las leyes de creación de dichos tributos (art. 179,3).

Por otra parte, el artículo 180 de la Constitución dispuso que:

La potestad tributaria que corresponde a los Municipios es distinta y autónoma de las potestades reguladoras que esta Constitución o las leyes atribuyan al Poder Nacional o Estadal sobre determinadas materias o actividades. 
Las inmunidades frente a la potestad impositiva de los Municipios, a favor de los demás entes políticosterritoriales, (sic) se extiende sólo a las personas jurídicas estatales creadas por ellos, pero no a concesionarios ni a otros contratistas de la Administración Nacional o de los Estados.

Con esta norma se persiguió, por una parte, deslindar de la materia tributaria las potestades reguladoras del Poder Nacional, en el sentido de que las actividades correspondientes a materias que puedan ser objeto de regulación por el Poder Nacional conforme al artículo 156 de la Constitución, no por ello quedan exentas de tributación municipal; y por la otra que la inmunidad tributaria de la República y de los Estados respecto de la tributación municipal, se extiende a las personas jurídicas estatales creadas por la República o por los Estados, pero no respecto de las empresas concesionarias ni a otros contratistas de las administraciones nacional o estadal.

Por otra parte, los Municipios están sometidos a las mismas limitaciones tributarias que los Estados previstas en el artículo 183 de la Constitución; y la competencia tributaria municipal, en todo caso, puede ser limitada por el Poder Nacional, en la legislación que la Asamblea Nacional dicte para:

... garantizar la coordinación y armonización de las distintas potestades tributarias; definir principios, parámetros y limitaciones, especialmente para la determinación de los tipos impositivos o alícuotas de los tributos estadales y municipales; así como para crear fondos específicos que aseguren la solidaridad interterritorial (art. $156,13)$,

\section{LAS COMPETENCIAS CONCURRENTES ENTRE LOS NIVELES TERRITORIALES DEL PODER PUBLICO}

La gran mayoría de las materias referidas a las competencias que, en los artículos 156, 164 y 178 se distribuyen entre los tres niveles territoriales del poder público, en realidad, son materias de la competencia concurrente entre la República, los estados y los municipios, o entre la República y los municipios o entre la República y los estados.

Estas materias objeto de competencias concurrentes son las que conforme al artículo 165 de la Constitución deben ser reguladas mediante leyes de bases dictadas por el Poder Nacional, lo que puede conducir a un condicionamiento excesivo por parte del Poder Nacional de los otros poderes territoriales; y además por leyes de desarrollo sancionadas por los Consejos Legislativos de los Estados. En todo caso, es obvio que estas leyes de bases no pueden referirse a las materias de la competencia exclu- 
siva, global o parcial, que se asignan a los Estados indicadas en el artículo 164, sino sólo a las materias de la competencia concurrente.

Sobre las leyes de bases, la Exposición de Motivos de la Constitución indica lo siguiente:

En cuanto a las competencias concurrentes se adopta la experiencia de Derecho Comparado en materia de descentralización y se asume que las leyes nacionales tienen la naturaleza de leyes de bases, en las que se establecen conceptos generales, básicos y orientadores; y las leyes estadales son leyes de desarrollo de esos principios básicos, lo que permitirá mejores condiciones para la delimitación de competencias.

En todo caso, la legislación sobre las materias de competencia concurrente debe estar orientada por los principios de interdependencia, coordinación, cooperación, corresponsabilidad y subsidiariedad que ya se han comentado; y cuando se dicten leyes de bases por el Poder Nacional, la Asamblea Nacional obligatoriamente debe someterlas a consulta de los Estados, a través de los Consejos Legislativos (art. 206). Los Consejos Legislativos de los Estados también tienen la iniciativa legislativa, ante la Asamblea Nacional, respecto de las leyes relativas a los Estados (art. 204,8).

\section{Antecedentes}

La noción de materia de la competencia concurrente entre las diversas entidades del Estado Federal (República, Estados y Municipios) se elaboró a finales de la década de los setenta con motivo de la elaboración de los Proyectos de Constitución de los Estados Aragua y Yaracuy ${ }^{10}$; para identificar lo que podían ser, en consecuencia, materias de la competencia de los Estados, pero que no les correspondían en forma exclusiva, sino que en las mismas concurrían los diversos niveles político territoriales. En particular, las competencias concurrentes se identificaron por deducción en todos los casos en los cuales la Constitución Nacional atribuía determinadas competencias y responsabilidades al «Estado».

En el constitucionalismo venezolano, dada la forma federal del Estado, esta expresión «Estado» comprende toda la organización política del Estado Federal y, por tanto, a estos efectos competenciales, tan

\footnotetext{
${ }^{10}$ Véase Allan R. BREWER-CARÍAs, «El régimen de los Estados en la Federación venezolana. Con ocasión de la Exposición de Motivos de la Ley Orgánica del Estado Aragua» en Asamblea Legislativa del Estado Aragua, Proyecto de Ley Orgánica del Estado Aragua, Maracay, Agosto 1979, pp. 1 a 31 .
} 
«Estado» es la República como los Estados y los Municipios ${ }^{11}$; por ejemplo, cuando la Constitución señala que «El Estado protegerá a las familias como asociación natural de la sociedad...» (art. 75), ésta es una obligación que corresponde tanto de los órganos del Poder Nacional (la República) como de los órganos del Poder Estadal (Estados) y de los órganos del Poder Municipal (Municipios). Por tanto, cuando la Constitución utiliza la expresión «Estado» no sólo se refiere al «Estado nacional» sino a todos los niveles territoriales derivados de la división del Poder Público.

En esta orientación se dictaron, por tanto, las Constituciones de Yaracuy, en $1979^{12}$ y Aragua, en $1980^{13}$, y varias otras Constituciones estadales, y como culminación del proceso se sancionó la Ley Orgánica de Descentralización, Delimitación y Transferencia de Competencias del Poder Público de 1989, en cuyo artículo 4 se enumeraron, conforme a la Constitución de 1961, las «competencias concurrentes» entre la República y los Estados a los efectos de promover la transferencia progresiva de la República hacia los Estados de «los siguientes servicios que actualmente presta el Poder Nacional»:

Art. 4: En ejercicio de las competencias concurrentes que establece la Constitución, y conforme a los procedimientos que esta Ley señala, serán transferidos progresivamente a los Estados los siguientes servicios que actualmente presta el Poder Nacional:

1. La planificación, coordinación y promoción de su propio desarrollo integral, de conformidad con las leyes nacionales de la materia;

2. La protección de la familia, y en especial del menor;

3. Mejorar las condiciones de vida de la población campesina;

4. La protección de las comunidades indígenas atendiendo a la preservación de su tradición cultural y la conservación de sus derechos sobre su territorio;

5. La educación, en los diversos niveles y modalidades del sistema educativo, de conformidad con las directrices y bases que establezca el Poder Nacional;

6. La cultura en sus diversas manifestaciones, la protección y conservación de las obras, objetos y monumentos de valor histórico o artístico;

\footnotetext{
${ }^{11}$ Véase Allan R. Brewer-Carías, Instituciones Políticas y Constitucionales, Tomo II, El Poder Público: Nacional, Estadal y Municipal, Caracas 1996, pp. 387 y sigts.

${ }^{12}$ Constitución de 31-12-79, G.O. del Estado Yaracuy de 01-01-80.

${ }^{13}$ Constitución de 03-12-80, G.O. del Estado Aragua de 04-12-80.
} 
REAL 291 (HOMENAJE AL PROFESOR SEBASTIÁN MARTÍN-RETORTILLO)

7. El deporte, la educación física y la recreación;

8. Los servicios de empleo;

9. La formación de recursos humanos, y en especial los programas de aprendizaje, capacitación y perfeccionamiento profesionales; y, de bienestar de los trabajadores;

10. La promoción de la agricultura, la industria y el comercio;

11. La conservación, defensa y mejoramiento del ambiente y los recursos naturales;

12. La ordenación del territorio del Estado de conformidad con la Ley Nacional;

13. La ejecución de las obras públicas de interés estadal con sujeción a las normas o procedimientos técnicos para obras de ingeniería y urbanismo establecidas por el Poder Nacional y Municipal, y la apertura y conservación de las vías de comunicación estadales;

14. La vivienda popular, urbana y rural;

15. La protección a los consumidores, de conformidad con lo dispuesto en las leyes nacionales;

16. La salud pública y la nutrición, observando la dirección técnica, las normas administrativas y la coordinación de los servicios destinados a la defensa de las mismas que disponga el Poder Nacional;

17. La investigación científica; y

18. La defensa civil.

Siguiendo la misma orientación de estos antecedentes constitucionales y legales, en nuestro criterio pueden distinguirse las siguientes materias como de la competencia concurrente entre los niveles nacional, estadal y municipal del Poder Público.

\section{El régimen de la seguridad y protección ciudadana: policía y administración de riesgos}

El artículo 55 de la Constitución garantiza el derecho de toda persona a la protección por parte del Estado, a través de los órganos de seguridad ciudadana regulados por ley, frente a situaciones que constituyen amenaza, vulnerabilidad o riesgo para la integridad física de las personas, sus propiedades, el disfrute de sus derechos y el cumplimiento de sus deberes». La norma asigna al «Estado» la obligación de proteger, y la expre- 
sión «Estado» comprende la totalidad de los entes que conforman su organización política como Estado Federal. En consecuencia, esta obligación corresponde, concurrentemente, a la República, a los Estados y a los Municipios, como lo confirma expresamente el artículo 332 de la Constitución, tanto por lo que se refiere a la policía como a la administración de riesgos y emergencias, al indicar que la función de los órganos de seguridad ciudadana constituye una «competencia concurrente». Esto lo confirma, además, el artículo 184 de la Constitución al reconocer como competencia de los Estados y los Municipios la materia de «prevención y protección vecinal».

En cuanto a la policía, además, como se ha visto, el Poder Nacional tiene competencia exclusiva en materia de «policía nacional» (art. 156,6), correspondiendo al Ejecutivo Nacional organizar, de conformidad con la ley, un cuerpo uniformado de policía nacional (art. 332). El Poder Estadal tiene competencia exclusiva para «la organización de la policía y la determinación de las ramas de este servicio atribuidas a la competencia municipal, de conformidad con la Ley» (art. 164,6) y el Poder Municipal tiene competencia exclusiva, «en cuanto concierne a la vida local», en materia de «prevención y protección vecinal y servicios de policía municipal, conforme a la legislación nacional aplicable» (art. 178,7). Además, se atribuye a los Municipios competencia exclusiva, también en cuanto concierne a la vida local, en materia de servicios de «protección civil» (art. 178,4) y de «servicios prevención y protección, vigilancia y control de los bienes y las actividades relativas a las materias de la competencia municipal» (art. 178,5).

Esto implica, también, una concurrencia de competencias en materia de administración de riesgos y emergencias: el artículo 156, ordinal 9 atribuye al Poder Nacional el régimen de la administración de riesgos y emergencias, y el artículo 332 encarga al Ejecutivo Nacional, de conformidad con la ley, organizar un cuerpo de bomberos y administración de carácter civil y una organización de protección civil y administración de desastres, como parte de los órganos de seguridad ciudadana. La misma norma considera como una competencia concurrente de los Estados y Municipios la función de los órganos de seguridad ciudadana, por lo que aquellos, conforme con los artículos 164,8 y 178,4, 5, y 7, de conformidad con la legislación nacional, pueden establecer los servicios respectivos.

\section{Régimen del desarrollo económico}

La legislación básica en materia de economía, como se ha dicho, es una competencia exclusiva del Poder Nacional (art. 156,11,15,17,18 y 21). Sin 
embargo, el régimen de ordenación y promoción del desarrollo económico es competencia concurrente de los tres niveles territoriales de gobierno.

\section{A. Ordenación y promoción del desarrollo económico y social}

En efecto, los artículos 112, 299, 308, 309 y 310 de la Constitución atribuyen competencia al «Estado» para promover la iniciativa privada con facultad para dictar medidas para planificar, racionalizar y regular la economía e impulsar el desarrollo integral del país; promover el desarrollo armónico de la economía nacional; proteger la artesanía e industrias populares; velar por la creación y fortalecimiento del sector turístico nacional; $\mathrm{y}$ proteger y promover la pequeña y mediana industria.

De nuevo, la atribución al «Estado» de estas competencias exige precisar que dicha expresión comprende a los diversos niveles territoriales que conforman la organización política del Estado: la República, los Estados y los Municipios. Por tanto, aquí también se trata de una materia de la competencia concurrente que se corrobora en otras normas constitucionales, que atribuyen a los órganos del Poder Público competencia exclusiva en aspectos específicos de esta materia.

En efecto, la Constitución asigna a la Asamblea Nacional la competencia exclusiva para aprobar las líneas generales del plan de desarrollo económico y social (art. 187,8) y atribuye al Presidente de la República competencia exclusiva para formular el Plan Nacional de Desarrollo y dirigir su ejecución previa aprobación de la Asamblea Nacional (art. 236,18). Ello implica, por supuesto, que puede y debe haber planes estadales y municipales de desarrollo, para lo cual los Estados y Municipios tienen competencia. Por ello, en cada Estado debe existir un Consejo Estadal de Planificación y Coordinación (art. 166) y en cada Municipio, un Consejo Local de Planificación (art. 182). Los Municipios, además, tienen competencia exclusiva, en cuanto concierne a la vida local, en materia de ordenación y promoción del desarrollo económico y social (art. 178).

Por otra parte, como órgano intergubernamental, el Consejo Federal de Gobierno tiene la misión de planificar y coordinar las políticas y acciones de los tres niveles territoriales para el desarrollo del proceso de descentralización (art. 185).

\section{B. Turismo}

El artículo 310 de la Constitución regula al turismo como una actividad económica de interés nacional, prioritaria para el país en su estrategia de diversificación y desarrollo sostenido. En tal sentido, como consecuencia, 
atribuye al «Estado» la obligación tanto de dictar medidas que garanticen el desarrollo del turismo, como de velar por la creación y fortalecimiento del turismo nacional.

El «Estado», en esa norma, igualmente, es tanto el Estado Nacional (República) como los Estados federados y los Municipios, configurándose la materia como de la competencia concurrente entre los tres niveles territoriales.

Además, debe destacarse que, en particular, en materia turística el Poder Nacional tiene asignada competencia exclusiva para la política nacional y legislación en materia de turismo (art. 156,23), por lo que también existe una política estadal y municipal en la materia que corresponde a los Estados y Municipios. En especial, a estos últimos se asigna competencia exclusiva, en cuanto concierne a la vida local, en materia de «turismo local» (art. 178,1).

\section{Promoción del desarrollo rural y seguridad alimentaria}

Los artículos 305, 306 y 307 de la Constitución también atribuyen al «Estado» obligaciones de promover el desarrollo rural integral; promover las condiciones para fomentar la actividad agrícola y la agricultura sustentable, a fin de garantizar la seguridad alimentaria, y alcanzar niveles estratégicos de autoabastecimiento; proteger las comunidades y asentamientos de pescadores artesanales; proteger y promover las formas asociativas y particulares de propiedad, y velar por la ordenación sustentable de las tierras de vocación agrícola. Estas obligaciones del «Estado», de nuevo, corresponden en forma concurrente a todos los entes que conforman la organización política del mismo, es decir, a la República, a los Estados y a los Municipios.

Por otra parte, como se ha visto, en la materia el Poder Nacional tiene competencia exclusiva para dictar la «legislación agraria» (art. 156,32) y definir la política nacional en materia tanto de seguridad alimentaria (art. $156,23)$ como de producción agrícola, ganadera, forestal y pesquera (art. 25).

Por tanto, los Estados y Municipios tienen competencia, respectivamente, para definir la política estadal y municipal en materia de seguridad alimentaria y para la producción agrícola, ganadera, pesquera y forestal.

\section{Ciencia y tecnología}

El artículo 110 de la Constitución también atribuye al «Estado» diversas obligaciones y misiones en materia de ciencia, tecnología, conoci- 
miento, innovación y sus aplicaciones y los servicios de información necesarios por ser instrumentos fundamentales para el desarrollo económico, social y político del país, con obligaciones de fomento y desarrollo de esas actividades.

De nuevo, el «Estado», en la Constitución comprende a la República, a los Estados y a los Municipios, entidades que, por tanto, tienen competencia concurrente en la materia.

\section{E. Información económico-social}

El artículo 156, ordinal 18 de la Constitución, como se ha dicho, atribuye al Poder Nacional competencia exclusiva en materia de «censos y estadísticas nacionales».

En consecuencia, los Estados y Municipios tendrían competencia concurrente en materia de censos y estadísticas estadales y municipales, respectivamente.

\section{F. Publicidad comercial}

En cuanto a la publicidad comercial, el artículo 178 , ordinal $3 .^{\circ}$ de la Constitución, como antes indicamos, atribuye a los Municipios competencia exclusiva en la materia «en cuanto concierne a los intereses y fines específicos municipales».

Por tanto, el Poder Nacional y el Poder Estadal tendrían competencia en la materia en cuanto concierne a los fines específicos nacionales o estadales, respectivamente.

\section{Régimen del desarrollo social}

En el campo del desarrollo social, conforme a las previsiones constitucionales, puede decirse que todas las materias relativas al mismo son de la competencia concurrente, de todos a los órganos del Estado, es decir, de la República, de los Estados y de los Municipios.

\section{A. Asistencia y protección social}

Conforme a los artículos 75 a 81 de la Constitución, el «Estado» tiene un conjunto de obligaciones tendientes a asegurar la protección de las familias y de quienes ejerzan la jefatura de la familia; a garantizar asistencia y protección integral a la maternidad; a proteger el matrimonio entre 
hombre y mujer; a asegurar protección integral a los niños y adolescentes y a promover su integración progresiva a la ciudadanía activa; a crear oportunidades para estimular el tránsito productivo de los jóvenes a la vida adulta, su capacitación y acceso al primer empleo; a garantizar a los ancianos el pleno ejercicio de sus derechos y garantías, así como atención integral; respecto de los discapacitados, a garantizar el respeto a su dignidad humana, la equiparación de oportunidades, condiciones laborales satisfactorias y promover su formación, capacitación y acceso al empleo acorde con sus condiciones.

Todas estas responsabilidades, sin duda, corresponden en forma concurrente tanto a la República como a los Estados y Municipios.

La «legislación nacional» en la materia corresponde en forma exclusiva al Poder Nacional, pero, por ejemplo, la Constitución atribuye en forma expresa a los Municipios competencia exclusiva, en cuanto concierne a la vida local, en materia de servicios de protección a la primera y segunda infancia, a la adolescencia y a la tercera edad, así como en materia de servicios de integración familiar del discapacitado al desarrollo comunitario (art. 178,5).

Estos servicios públicos de asistencia y protección, dado el carácter de materia de competencia concurrente, también serían, en los términos del artículo 164,8 de la Constitución, servicios públicos estadales.

\section{B. Salud y sanidad}

Las obligaciones públicas en materia de salud, conforme a los artículos 83, 84 y 85 de la Constitución, también se atribuyen al «Estado», es decir, tanto a la República como a los Estados y Municipios. En consecuencia, se trata de servicios que son de la competencia concurrente de los tres niveles territoriales.

En la materia, sin embargo, como se ha dicho, el artículo 156,23 atribuye al Poder Nacional competencia exclusiva en materia de políticas y servicios nacionales de salud y de legislación sobre sanidad nacional y vegetal (art. 156,32). En particular, los artículos 84 y 85 precisan como competencia del Poder Nacional el establecimiento de un Sistema Público Nacional de Salud. En consecuencia, los Estados y Municipios tienen competencia en materia de políticas y servicios estadales y municipales de salud.

El Poder Nacional, además, tiene competencia exclusiva para dictar la legislación sobre sanidad animal y vegetal (art. 156, 32) y los Municipios tienen competencia exclusiva expresa, en cuanto concierne a la vida local, en materia de salubridad y atención primaria en salud (art. 178,5). 
En cuanto a los Estados, los servicios de salud como materia de la competencia concurrente, serían servicios públicos estadales (art. 164,8). Ello lo confirma, además, el artículo 184, al establecer la descentralización de los «servicios de salud» de los Estados y Municipios a las organizaciones comunitarias.

\section{Vivienda}

El artículo 82 asigna al «Estado en todos sus ámbitos» la obligación de satisfacer progresivamente el derecho de toda persona a la vivienda; por lo que se trata de una materia que corresponde, en forma concurrente, a la República, a los Estados y a los Municipios.

Además, la Constitución atribuye como competencia exclusiva del Poder Nacional la política nacional y la legislación en materia de vivienda (art. 156, 23), por lo que los Estados y Municipios tienen competencia en materia de políticas estadales y municipales de vivienda, respectivamente. Ello también lo confirma el artículo 184 de la Constitución.

Además, los Municipios tienen competencia expresa exclusiva, en cuanto concierne a la vida local, en materia de vivienda de interés social (art. 178,1) y de aplicación de la política inquilinaria conforme a la delegación prevista en la ley nacional (art. 178).

\section{Educación}

Los artículos 102 a 109 de la Constitución también asignan un conjunto de obligaciones al «Estado» en materia de educación, lo que conlleva a que la competencia en la materia sea concurrente entre la República, los Estados y los Municipios.

Por otra parte, como ya se ha indicado, el artículo 156,24 atribuye al Poder Nacional competencia exclusiva para las políticas y los servicios nacionales de educación.

En consecuencia, los Estados y Municipios tienen competencia, respectivamente, para las políticas y los servicios estadales y municipales de educación.

Los servicios de educación, por tanto, también serían servicios públicos estadales en los términos del artículo 164,8; y en cuanto a los Municipios, el artículo 178,5 les atribuye competencia exclusiva, en cuanto concierne a la vida local, en materia de educación preescolar. 
La competencia estadal y municipal en «servicios de educación», también la confirma el artículo 184 de la Constitución.

\section{E. Cultura y patrimonio histórico}

Los artículos 98 a 191 de la Constitución establecen también un conjunto de obligaciones, asignadas al «Estado», en materia de cultura y patrimonio histórico, cultural y arquitectónico lo que las configura como una de las materias de competencia concurrente entre la República, los Estados y los Municipios, que se ejerce de acuerdo con la legislación nacional en materia de «patrimonio cultural y arqueológico» (art. 156,32).

Además, como se indicó, el artículo 156,32 de la Constitución le asigna al Poder Nacional competencia exclusiva para dictar la legislación en la materia. El artículo 178, ordinales 1 y 5 le atribuyen en forma expresa competencia exclusiva a los Municipios, en cuanto concierne a la vida local, en materia de actividades e instalaciones culturales y de patrimonio histórico.

Los servicios culturales constituirían servicios públicos estadales, en los términos del artículo 164,8 de la Constitución.

El artículo 184 de la Constitución, además, confirma la competencia de los Estados y Municipios en materia de «servicios culturales».

\section{F. Deporte}

El artículo 111 de la Constitución atribuye al «Estado» la responsabilidad de asumir el deporte y la recreación como política de educación y salud, correspondiendo, por tanto, a la República, a los Estados y a los Municipios dicha responsabilidad.

El artículo 178,1, además, atribuye a los Municipios la competencia exclusiva, en cuanto concierne a la vida local, en materia de sitios de recreación; y el artículo 184 confirma la competencia de los Estados y Municipios en materia de «servicios de deporte».

\section{G. La protección a las comunidades indígenas}

Los artículos 119 a 125 de la Constitución, que regulan el régimen de los derechos de los pueblos indígenas, establecen una serie de obligaciones de protección y atención que corresponden al «Estado», es decir, a la globalidad de las entidades políticas que componen el Estado Federal: la República, los estados y los Municipios. 
Se trata, por tanto, de una materia de la competencia concurrente entre los tres niveles territoriales que se ejerce de acuerdo con la legislación nacional en materia de «pueblos indígenas» (art. 156,32), salvo en aspectos que expresamente alguna de dichas normas atribuye al «Ejecutivo Nacional», como la demarcación de las tierras indígenas (art. 119).

\section{H. La protección del trabajo}

Los artículos 87 y siguientes de la Constitución regulan los derechos laborales, y asignan al «Estado» un conjunto de obligaciones como la adopción de medidas para asegurar empleo, el fomento del empleo, y la protección del trabajo sin discriminación. En todos estos casos, las obligaciones asignadas al «Estado», sin duda, corresponden tanto a la República como a los Estados y Municipios. Se trata, por tanto, de una materia de competencia concurrente que se ejerce de acuerdo con la legislación nacional en materia de trabajo, previsión y seguridad sociales (art. 156,32).

\section{Régimen de la infraestructura y de la ordenación del territorio}

\section{A. Ordenación del territorio}

El artículo 128 de la Constitución atribuye al «Estado» competencia en materia de ordenación territorial, razón por la cual se trata de una competencia concurrente entre la República, los Estados y los Municipios.

Además, como se ha dicho, el artículo 156,23 de la Constitución le atribuye al Poder Nacional competencia exclusiva en cuanto a las políticas nacionales y la «legislación» en materia de ordenación de territorio, por lo que a los Estados y Municipios les corresponde la política estadal y municipal, respectivamente, en la ordenación del territorio de las respectivas entidades.

Adicionalmente, el artículo 178 le atribuye expresamente a los Municipios competencia exclusiva, en cuanto concierne a la vida local, en materia de «ordenación territorial», y el artículo 184 confirma la competencia de Estados y Municipios en la materia, por ejemplo, al referirse al «mantenimiento de áreas industriales».

\section{B. Ambiente}

En igual forma, los artículos 127 a 129 de la Constitución le asignan al «Estado» competencias en materia ambiental, lo que la configura como una de las materias de competencia concurrente entre la República, los Estados y los Municipios. 
Por otra parte, el artículo 156,23 de la Constitución, además, atribuye al Poder Nacional competencia exclusiva en cuanto a las políticas nacionales y la «legislación» en materia de ambiente y aguas, por lo que los Estados y Municipios tienen competencia en las políticas estadales y municipales en la materia.

Además, el artículo 178,4 le atribuye en forma exclusiva a los Municipios, en cuanto concierne a la vida local, competencias en materia de «protección del ambiente y cooperación con el saneamiento ambiental».

El artículo 184 de la Constitución, además, confirma la competencia de Estados y Municipios en materia de «servicios ambientales».

\section{Urbanismo}

En materia de urbanismo no hay en la Constitución una disposición que le asigne el carácter de competencia concurrente, salvo su inclusión como un aspecto urbano de la ordenación territorial que corresponde a los tres niveles de gobierno.

El artículo 184 de la Constitución, por otra parte, confirma la competencia tanto de los Estados como de los Municipios en materia de «mantenimiento y conservación de áreas urbanas».

Además, como se dijo, el Poder Nacional tiene competencia exclusiva para el establecimiento, coordinación y unificación de normas y procedimientos técnicos para obras de ingeniería, de arquitectura y de urbanismo y la legislación sobre ordenación urbanística (art. 156,19).

Además, el Poder Municipal tiene competencia exclusiva, en cuanto concierne a la vida local, en materia de ordenación urbanística, parques, jardines, plazas, balnearios, otros sitios de recreación, arquitectura civil, nomenclatura y ornato público (art. 178,1).

Se trata, por tanto, de una materia de la competencia concurrente entre el Poder Nacional, el Poder Estadal y el Poder Municipal.

\section{LAS COMPETENCIAS RESIDUALES}

Conforme a la tradición de los sistemas federales, los Estados tienen competencia en todo lo que no corresponda de conformidad con la Constitución a la competencia nacional o municipal (art. 164,11). Es lo que se denomina la competencia residual de los Estados. 
Sin embargo, en virtud de la competencia implícita a favor del Poder Nacional establecida en el artículo 156,33 de la Constitución, el residuo a favor de los Estados puede resultar aún más exiguo y dependiente del Poder Nacional. Dicha norma, en efecto, atribuye competencia al Poder Nacional en toda otra materia que la Constitución atribuya al Poder Público Nacional, o que le corresponda por si índole o naturaleza.

Además, como excepcionalmente ocurrió en la Constitución centralista y autoritaria de 1953, la Constitución de 1999 también estableció una competencia residual a favor del Poder Nacional, aun cuando reducida a la materia tributaria, al asignarle competencia en materia de impuestos, tasas y rentas «no atribuidos a los Estados y Municipios» por la Constitución y la ley (art. 156,12).

En consecuencia, en la Constitución de 1999 se estableció una doble competencia residual: a favor del Poder Nacional en materia tributaria; y el resto, a favor de los Estados.

\section{EL PRINCIPIO DESCENTRALIZADOR EN LAS COMPETENCIAS DEL PODER PÚBLICO}

A pesar de la sustancia centralista del esquema federal venezolano, el texto formal de la Constitución de 1999 puede decirse que está impregnado de descentralización: el artículo 4 declara al Estado como «Federal Descentralizado»; el artículo 6 precisa que el gobierno de la República y de las demás entidades políticas debe ser «descentralizado»; y el artículo 16 garantiza que la Ley Orgánica relativa a la división política del territorio nacional debe garantizar la «descentralización político-administrativa».

La descentralización, por otra parte, se declara como una política nacional, que debe profundizar la democracia, acercando al poder a la población, creando las mejores condiciones, tanto para el ejercicio de la democracia como para la prestación eficaz y eficiente de los cometidos estatales (art. 158).

Sin embargo, con un esquema de distribución de competencias, en gran parte sometidas a las regulaciones del Poder Nacional, la descentralización como política queda en manos de los órganos del Poder Nacional. Para ejecutarla, además, la Constitución prevé mecanismos de transferencias de competencias en cascada, desde el ámbito nacional hacia el ámbito local y hacia las comunidades. 
En efecto, el artículo 157 de la Constitución establece que la Asamblea Nacional, por mayoría de sus integrantes, puede atribuir a los Municipios o a los Estados determinadas materias de la competencia nacional, a fin de promover la descentralización. Esta norma, que sigue la línea que se había establecido en el artículo 137 de la Constitución de 1961, permite la descentralización hacia los Estados de competencias nacionales tanto exclusivas como concurrentes. En el primer caso, de llegar a darse, bastaría la decisión de la mayoría de los integrantes de la Asamblea Nacional para producir la modificación constitucional prevista en la norma, lo cual estimamos que no debió regularse así y más bien conservarse el voto calificado que establecía la Constitución de 1961.

Por otra parte, el artículo 165 de la Constitución establece que los Estados, a su vez, descentralizarán y transferirán a los Municipios los servicios y competencias que gestionen y que éstos estén en capacidad de prestar, así como la administración de los respectivos recursos, dentro de las áreas de competencias concurrentes entre ambos niveles del Poder Público. Corresponde a los Consejos Legislativos estadales regular dichos mecanismos de transferencia.

Por último, el artículo 184 de la Constitución precisa que la ley, que puede ser nacional, estadal o municipal, debe crear mecanismos abiertos y flexibles para que los Estados y los Municipios descentralicen y transfieran a las comunidades y grupos vecinales organizados los servicios que éstos gestionen, previa demostración de su capacidad para prestarlos, promoviendo:

1. La transferencia de servicios en materia de salud, educación, vivienda, deporte, cultura, programas sociales, ambiente, mantenimiento de áreas industriales, mantenimiento y conservación de áreas urbanas, prevención y protección vecinal, construcción de obras y prestación de servicios públicos. A tal efecto, pueden establecer convenios cuyos contenidos deben estar orientados por los principios de interdependencia, coordinación, cooperación y corresponsabilidad.

2. La participación de las comunidades y de ciudadanos o ciudadanas, a través de las asociaciones vecinales y organizaciones no gubernamentales, en la formulación de propuestas de inversión ante las autoridades estadales y municipales encargadas de la elaboración de los respectivos planes de inversión, así como en la ejecución, evaluación y control de obras, programas sociales y servicios públicos en su jurisdicción. 
3. La participación en los procesos económicos estimulando las expresiones de la economía social, tales como cooperativas, cajas de ahorro, mutuales y otras formas asociativas.

4. La participación de los trabajadores o trabajadoras y comunidades en la gestión de las empresas públicas mediante mecanismos autogestionarios y cogestionarios.

5. La creación de organizaciones, cooperativas y empresas comunales de servicios, como fuentes generadoras de empleo y de bienestar social, propendiendo a su permanencia mediante el diseño de políticas en las cuales aquellas tengan participación.

6. La creación de nuevos sujetos de descentralización a nivel de las parroquias, las comunidades, los barrios y las vecindades a los fines de garantizar el principio de la corresponsabilidad en la gestión pública de los gobiernos locales y estadales y desarrollar procesos autogestionarios y cogestionarios en la administración y control de los servicios públicos estadales y municipales.

7. La participación de las comunidades en actividades de acercamiento a los establecimientos penales y de vinculación de éstos con la población. 